\title{
DEVELOPMENT OF A QUANTIATIVE EVALUATION TOOL TO SUPPORT THE DEVELOPMENT PROCESS OF INDUSTRY 4.0 PRODUCTION EQUIPMENT
}

\author{
Ünal, Esra; Köhler, Christian \\ htw saar, Saarland University of Applied Sciences
}

\begin{abstract}
One of the main problems in the implementation of Industry 4.0 is the assessment of the added technical and economic value of the new digital and other technological opportunities. This can already be observed during the elaboration of solution alternatives during the development of new industry 4.0 work systems. In order to support the developers of these systems in their decision-making, this contribution introduces a quantitative evaluation approach based on the combination of an extension of the CPM/PDD approach with an industry 4.0 maturity model and an identification scheme for process losses.
\end{abstract}

Keywords: Industry 4.0, Decision making, Evaluation

Contact:

Köhler, Christian

htw saar, Saarland University of Applied Sciences

Business School

Germany

christian.koehler@htwsaar.de 


\section{INTRODUCTION}

Industry 4.0 is one of the biggest trends in industry and production. Thus, many industrial companies are increasingly concerned with the assessment of (technical) feasibility and implementation of this vision. According to Ustundag et al. (2018), Industry 4.0 stands for the establishment of intelligent and communicative systems including machine-to-machine communication and human-machine interaction. Briefly, Industry 4.0 is based on 8 fundamental technologies: adaptive robotics, data analytics and artificial intelligence (big data analytics), simulation, embedded systems, communication and networking such as Industrial Internet, cloud systems, additive manufacturing and virtualization technologies. Even though the, so called, 4th Industrial Revolution is high in trend and on everyone's agenda, only a small percentage of companies have accomplished a successful application ( $\mathrm{PwC}$, 2018). Difficulties appear especially in identification of goals and concrete benefits of solutions in the Industry 4.0 environment. The result of a study conducted by the market research institute TNS Emnid shows where to find the main cause: "Uncertainty about economic benefits is the biggest challenge for Industry 4.0" (PwC \& Strategy\&, 2014). One of the major reasons for this is that the economic effects can no longer be determined solely via manufacturing costs. The forecasted savings in manufacturing costs by Industry 4.0 are only between 6 and $20 \%$, whereas greater effects are expected in the periphery, such as a 20 to $50 \%$ reduction in indirect personnel costs, a 40 to $50 \%$ reduction in product launch costs, a 50 to $70 \%$ reduction in throughput times or savings of 40 to $70 \%$ related to engineering change costs (Wildemann, 2018). This is partly due to the fact that the expected added value by Industry 4.0 is of a rather qualitative nature: e.g. flexibility or adaptability to react to market changes and production of batch size one, improvement of process quality, better utilisation of existing capacities through networking and transparency (Kiel et al., 2017).

For the designer of Industry 4.0 production equipment, the challenge is to realize these added values through the right design and selection of technologies. In doing so, technologies are increasingly being used (e.g. from ICT) that have a significantly shorter innovation and life cycle than traditional machines and systems (Moon et al., 2018). This results in the overarching motivation of the research project to support the designer in his decision-making process in a way that enables the designer to develop Industry 4.0 production equipment in a demand-oriented manner.

The design of an Industry 4.0 production equipment can be regarded as a cross-industry innovation (Vullings and Heleven, 2015), since existing technologies and concepts from other industries are essentially transferred into a new context. Thus, the design process can be seen as the active selection of an existing solution pattern and its evaluation in the overall context of the system. This is a process similar to the CPM/PDD approach according to Weber (2005). Although the CPM/PDD model has already been applied to manufacturing systems (Deubel et al., 2006), it has not been applied to Industry 4.0 production equipment or in particular to assembly systems. Furthermore, there is hardly any information within the descriptions of CPM/PDD regarding the application of the evaluation step, which results from the interaction with the relations and actual properties of the product under development. With the motivation to remedy this situation, this article deals with the following research questions: "How can Weber's CPM/PDD approach be applied to the design of Industry 4.0 work systems?" and "What can a relation look like that enables an evaluation of Industry 4.0 added values with the help of the CPM/PDD approach?"

In order to answer these, the key components of the CPM/PDD model will be presented and enhanced (section 2), followed by a possible implementation of this concept (section 3) and a conclusion (section 4).

\section{ADAPTION OF THE CPM/PDD APPROACH TO THE SPECIFIC PROBLEM}

\subsection{Basic idea of the CPM/PDD approach}

This summary of the basic ideas of the CPM/PDD approach is based on Weber (2005). The original intention of the Characteristics-Properties Modelling / Property-Driven Development (CPM/PDD) approach is to model products and product development processes. Core of the CPM/PDD approach is a clear distinction between Characteristics and Properties (Weber and Werner, 2000):

- $\quad$ Characteristics $\left(\mathrm{C}_{\mathrm{i}}\right)$ represent the shape and the structure of a product (e.g. geometry, BOM, materials etc.). They can be directly established, assigned and modified by the designer. 
- Properties $\left(\mathrm{P}_{\mathrm{j}}\right)$ represent the behaviour of a product (e.g. weight, manufacturability, function, cost, user friendliness etc.). Those cannot be directly established by the designer; they can only be indirectly influenced by changing the depending Characteristics.

Relations $\left(\mathrm{R}_{\mathrm{j}}\right)$ are introduced to represent the interrelations between Characteristics and Properties. The connection of Characteristics, Relations and Properties can be depicted in a network-like structure (see Figure 1). In order to describe the product development process, two types of Relations between Characteristics and Properties can be distinguished:

- Synthesis: based on given/required Properties appropriate product Characteristics are established or assigned

- Analysis: based on known/given Characteristics of a product its Properties are determined.

Thus, the CPM/PDD approach describes product development as a repeated sequence of synthesis, analysis and evaluation steps. The evaluation step compares the "designed" Property values with the Required Properties $\left(\mathrm{RP}_{\mathrm{j}}\right)$. The difference between the existing and Required Properties $(\Delta \mathrm{P})$ is understood as the driver of the next iteration, i.e. it indicates which Properties need to be changed by modifying the related Characteristics. The internal relations between the Characteristics are represented by Dependencies $\left(\mathrm{D}_{\mathrm{x}}\right)$. External Conditions $\left(\mathrm{EC}_{\mathrm{j}}\right)$ are used to represent external influences on the design and can be understood as inputs to the Relations and thus the analysis or synthesis step. This means that the result of the evaluation step is only valid under consideration of existing or estimated External Conditions. A special type of External Conditions are the $X$-Systems, which the product to be developed encounters during its life cycle. An example of an X-System can be the assembly system in which the product is later manufactured. X-Systems themselves can again be described by Characteristics and Properties and have so far been less the focus of research work in the context of CPM/PDD (Crostack et al., 2014). Recurring partial solutions (e.g. machine elements) can be represented as Solution Patterns.

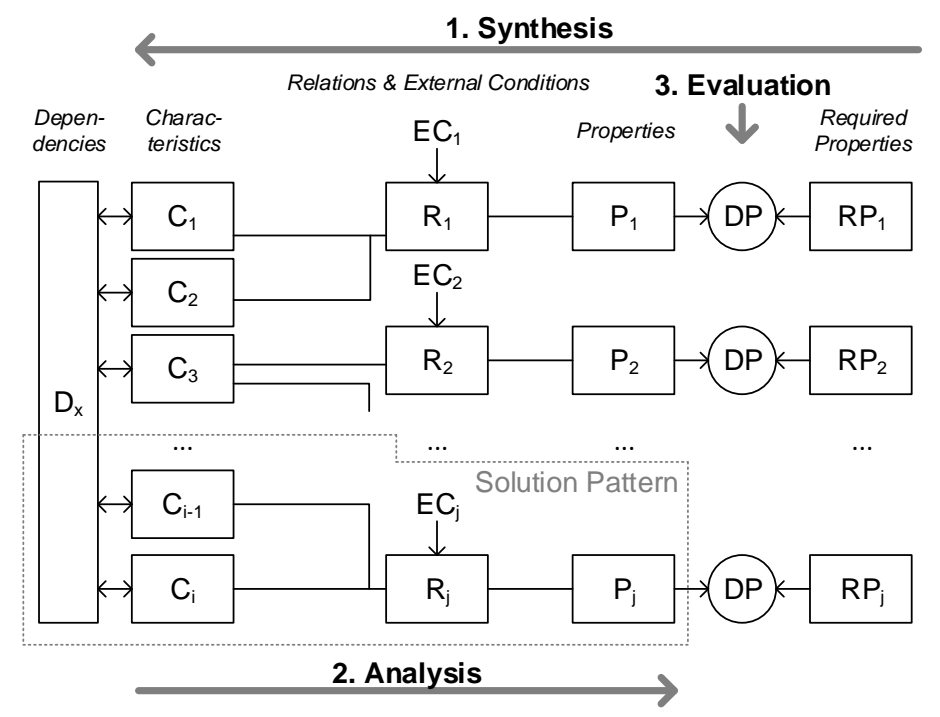

Figure 1. The CPM/PDD-model (cf. Köhler et al., 2008 and Wanke et al., 2007)

\subsection{CPM/PDD based model of an assembly system}

CPM/PDD mainly focuses on the design of products and its development process, but assembly systems are also briefly mentioned in the model (Weber, 2005). As mentioned above, Deubel et al. (2006) adapted the idea of Characteristics and Properties for manufacturing systems in order to achieve a requirement-driven planning concept: While product design with all its factors and influences was previously on a single level, the derived idea uses a three-level model for manufacturing systems. A hierarchical distinction is made between systems, machine and components view. These levels are connected by interdependencies of Characteristics and Properties. Characteristics of the higher level are transferred as Properties of the lower one - from system to machine and from machine to component. Taking a milling machine as an example, the required precision at the "machine" level represents a Required Property and leads to the Characteristic frame stiffness. This frame stiffness itself represents at a level lower a Required Property and is dependent e.g. on the Characteristic frame material. 
Originally manufacturing systems are mapped as external conditions in Weber's model and illustrate certain boundary conditions under which the product development takes place (Weber, 2005). The transfer of the model to manufacturing systems can be seen as a reversal of this relationship (Deubel et al., 2006). To understand that relationship, this contribution puts its focus on assembly systems enhanced by Industry 4.0 technologies. These represent a special form of manufacturing systems. On the other hand, a production equipment also represents a specific type of a product. This allows the adoption of CPM/PDD to the development of the product 'Industry 4.0 assembly system'. To do this, the CPM/PDD approach needs to be adapted on the basis of specific considerations.

\subsubsection{Process model - based on PDD}

In comparison to a typical product development project, many different people, departments and companies are involved in the planning and elaboration of an Industry 4.0 production equipment, but the trigger is always a product demanded by customers (Bauernhansl et al., 2014), i.e. more collaboration is required in the product development process (Jahn, 2017). Considering assembly systems as products, the requirements are summarised in a specification sheet. Typical aspects are productivity, efficiency, throughput time, cycle time, flexibility, availability or mean time to repair. Properties can also be derived or predetermined from the product that will be produced (Westkämper, 2006a, 2006b).

The process part of the CPM/PDD approach consists of multiple repetitions of synthesis, analysis and evaluation steps aiming at meeting the Required Properties $\mathrm{RP}_{\mathrm{j}}$ by minimising differences between actual and Required Properties $\left(\Delta \mathrm{P}_{\mathrm{j}}\right.$, see Figure 1) (Weber, 2005). This also remains valid for assembly systems until all factors are determined and deduced. The difference between actual and Required Properties is a measure for the success of the development (Weber, 2005) and thus the potential economic benefit of the equipment.

Nevertheless, it is possible to derive a different way of planning manufacturing systems. Therefore, the developed approach used for machine tools can be used as basis. This concept by Weck and Brecher (2006) describes the design process of machine tools as component-independent planning. This design process can be transferred and extended to assembly systems. Assembly systems can be seen as a composition and concatenation of several complex and different components or modules. With reference to Weber's model, these modules represent Solution Patterns. They correspond to an aggregation of Properties and Characteristics of a product and their relations (Feldmann and Slama, 2001).

At the end of the 1960s, the tendency to computer-aided product development processes gave rise to the plan of storing developed and commercially distributed solutions in catalogue systems in order to make them more easily retrievable and thus reusable (Weber, 2005). The aim was to give the product designer impulses and suggestions for the development of products on the one hand and guarantee a certain security in product planning (e.g. costs and time) on the other hand. The same can be said about the design of assembly systems: these systems are merely composed of modules and hence Solution Patterns. This shifts the development process of Industry 4.0 assembly systems towards a configuration problem.

The trigger of the planning of an assembly system is the product in demand, which has to be manufactured. This object defines the assembly sequence by design, composition and structure (Lotter and Wiendahl, 2012). It specifies which process steps, machines and equipment are necessary. The determination of the required assembly system is done similar to a modular concept by the selection and composition of single modules (Solution Patterns), based on individual process steps. The main focus lies here on the module type, whereas the specification of this module is carried out in the phase before ramp-up and production (Bullinger, 1986).

\subsubsection{Product model - based on CPM}

An assembly system is a product that is designed to manufacture other products. Although it differs from an everyday product, there are similarities but also differences or novelties in the derivation of the model. CPM's exact distinction between Characteristics and Properties is maintained for assembly systems, but, to keep it manageable, in a slightly more general way. All aspects that can be directly influenced by the designer of the assembly system are seen as Characteristics. Therefore, all factors that are unaffectable are considered as Properties. Factors that can be directly influenced are, for example, the layout arrangement of the assembly system, the choice of equipment (e.g. screw technology) or the material feeding. Also included are aspects such as manpower requirements or degree of automation. 
Another similar aspect is the list with Required Properties, which includes the product to assemble and thus represents the trigger of the assembly system development. It also consists of typical factors that are used to describe the economic efficiency of the production system (only indirectly influenceable) and contains key figures such as utilisation rate, productivity, throughput time as well as costs.

However, there are also certain differences regarding assembly systems as a product. In the assembly system, the main focus lies on the action of assembling, which means on the process step itself. A process step is a logical work action consisting of one or more operation types with a defined goal. The goal is to change the (current) condition of the assembled product or its components, for example combining single components to one module. Many of these process steps are derived and specified by this product itself. Taking a car as an example, the electrical interior must be installed before assembling the covers. The desired result could not be achieved if the order was different. This means in some points the assembly sequence is already fixed and not variable. This represents a new group of influences. Within the CPM product model, these influences could be considered either as Required Properties or as External Conditions. In both cases a direct influencing of the factors is not possible. Both considerations are conceivable. Below, an attempt to elaborate a potential subdivision and classification is outlined.

Based on the already developed approach of requirement-driven planning of manufacturing system, Characteristics of the upper level (e.g. machine) are used as Properties of the lower one (e.g. component) (Deubel et al., 2006). Hence fixed Characteristics of the product to be produced mirror the Required Properties of the assembly system. In this case the Characteristic (of the product) assembly sequence becomes a Required Property for the assembly system. By executing the synthesis step, the derivation of the associated Characteristics of the assembly system (e.g. the selection of a screw technology or the workplace layout) is possible now.

In order to break down the assembly sequence into influenceable Characteristics, the Methods Time Measurement (MTM) - Universal Analysing System (UAS) can be used here. In MTM each process step is reduced to certain basic movements with the aim to determine the time that is required to perform an operation (Karger and Bayha, 1987). The basic movements for assembly can be divided into reach, grasp, move, position and release.

The single movements in turn lead to the Characteristic type of execution. This involves how the operation / movement will be performed. It can be conducted by an employee, but also by a machine or a robot. Basically, it's about the equipment and resources. Figure 2 illustrates this.

\begin{tabular}{|l|}
\hline $\begin{array}{c}\mathbf{C}_{\mathrm{i}} \text { : Type of } \\
\text { execution }\end{array}$ \\
movements
\end{tabular} \mid \begin{tabular}{c|c|}
$\mathbf{R}_{\mathrm{j}}$ : Basic \\
movementy \\
sequence
\end{tabular}

Figure 2. Synthesis assembly system - Required Properties

Taking the assembly of a bearing cap using screws as an example: it must first be positioned and held in place. Basic movements would be reaching, grasping and moving. It is the designer's decision how these movements should be executed. A worker can do this without problems, but also a fully automated system. A collaborative man-machine-solution is a third possibility.

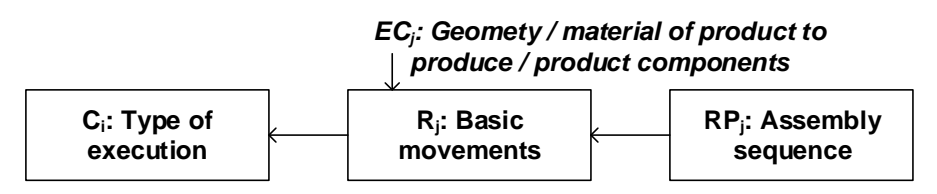

Figure 3. External Conditions derived from product

Although the decision on the realisation of the Characteristics is made by the designer, the choice is tied to certain conditions. Referring to the example above, the selection of the equipment / resources also depends for example on the geometry or material of the bearing cap. If the designer wants to use a robot, the geometry determines the gripper. Smaller parts require different tools than a voluminous one. The material has an effect on the maximum force of the gripper and must be adapted accordingly (e.g. steel allows a higher gripping force than plastic). This leads to the second class, in which influences derived from the product can be categorised. These do not Required Properties, but influence the relationship between them and Characteristics. According to Weber (2005), these type of boundary conditions are considered as External Conditions. This results in an inverted perspective of the original CPM/PDD approach. As already mentioned, the production equipment is originally 
intended to be an X-System and thus an External Condition. In this case, parts of the product themselves become External Conditions (see Figure 3).

To sum it up, the assembled product specifies requirements for the assembly system (Required Properties) on the one hand and on the other hand it can influence the relationship between Characteristics and Properties of the assembly system (External Conditions). But, there are also Properties that are not necessarily related to the product and only concern the assembly system. These are also defined as Required Properties. This indicates the need for a more differentiated classification:

- $\quad$ Properties specified by the product are named Required Properties derived from product $\left(\mathrm{RP}_{\mathrm{pj}}\right)$.

- $\quad$ System specific Properties are identified as $\mathrm{RP}_{\mathrm{sj}}$.

There are also External Conditions that are unrelated to the product. In order to enable a more precise identification, the distinction between system and product-related is also made here: $\mathrm{EC}_{\mathrm{sj}}$ and $\mathrm{EC}_{\mathrm{pj}}$. Table 1 shows a number of examples per category.

Table 1. Examples for different classifications by transferring CPM to assembly systems

\begin{tabular}{|l|l|l|l|}
\hline $\mathbf{R P}_{\mathbf{s j}}$ & $\mathbf{R P}_{\mathbf{p j}}$ & $\mathbf{E C}_{\mathbf{s j}}$ & $\mathbf{E C}_{\mathbf{p j}}$ \\
\hline utilisation rate & assembly sequence & budget of company & material \\
productivity & batch size & legal regulations & geometry / dimensions \\
throughput time & assembly process & work safety & customer demands \\
costs & assembly direction & environmental protection & tolerance specifications \\
personnel & ergonomics & \\
degree of automation & & available space & \\
area requirement / layout & & quality standards & \\
\hline
\end{tabular}

There are numerous examples here, similar to the standard (possible) product described in CPM/PDD (Weber, 2005). The difficulty lies in integrating the influences and relevant aspects accordingly. Developing assembly systems can be conducted using the Solution Patterns defined in the CPM/PDD model, based on the previously defined or pre-defined Characteristics and consequently Required Properties and vice versa. The question that needs to be clarified is how to compare and evaluate different Solution Patterns, especially with regard to Industry 4.0. Especially since the use of a Solution Pattern does not necessarily imply that all of its Characteristics and Properties are actually relevant or intentionally selected. However, using one solution pattern in combination with another can create and enable additional possibilities and new benefits. Taking for example a screw technique which, in addition to monitoring torque and angle of rotation, has the function of outputting the process result as a signal. This additional function only becomes an added value (e.g. from a quality point of view) if it is combined with a device that only opens when the screw connection was in order. The following chapter provides an overview of the advantages of Industry 4.0, with a particular focus on added values that do not directly come into mind.

\section{PREPARATORY WORK FOR THE EVALUATION OF THE ADDED VALUE OF INDUSTRY 4.0 TECHNOLOGIES}

In order to allow a first qualitative assessment it is necessary that a Relation in CPM/PDD between the new digital/technological opportunities and the additional values for the product can be established. For this purpose, a tried and tested maturity model for Industry 4.0 is combined with added values of Industry 4.0.

\subsection{VDMA Guideline Industry $\mathbf{4 . 0}$ maturity levels}

Problems associated with the adaption of Industry 4.0 approaches were also recognised by the German Mechanical Engineering Industry Association (VDMA). In order to support companies in the introduction of business models for Industry 4.0, the so-called Guideline Industry 4.0 has been developed (VDMA, 2015). It presents a kind of a maturity level oriented approach that picks up on visions around Industry 4.0 and reduces them to viable development stages. Its aim is to provide companies with an instrument for developing their own Industry 4.0 business models and thus facilitate Industry 4.0 implementations. One key element proposed is the Industry 4.0 toolbox. The 
toolbox combines different levels of implementation of Industry 4.0 with regard to product innovations and production applications. Figure 4 shows a section from this toolbox for better clarity.

\begin{tabular}{|l|l|l|l|l|l|}
\hline \multicolumn{5}{|c|}{ VDMA Toolbox Industry 4.0 / Products } \\
\hline Category & Maturity Level 1 & Maturity Level 2 & Maturity Level 3 & Maturity Level 4 & Maturity Level 5 \\
\hline $\begin{array}{l}\text { Integration of } \\
\text { sensors / acutators }\end{array}$ & $\begin{array}{l}\text { No use of sensors / } \\
\text { acutators }\end{array}$ & $\begin{array}{l}\text { Sensors / actuators } \\
\text { are integrated }\end{array}$ & $\begin{array}{l}\text { Sensor readings are } \\
\text { processed in the } \\
\text { product }\end{array}$ & $\begin{array}{l}\text { Data is evaluated for } \\
\text { analyses by the } \\
\text { product }\end{array}$ & $\begin{array}{l}\text { The product } \\
\text { independently } \\
\text { responds based on } \\
\text { the gained data }\end{array}$ \\
\hline$\ldots$ & $\ldots$ & $\ldots$ & $\ldots$ & $\ldots$ \\
\hline
\end{tabular}

Figure 4. Example of Guideline Industry 4.0 - extract of toolbox (VDMA, 2015)

All implementation stages are linked to basic technologies to point out further potentials and to make diverse ideas and approaches of Industry 4.0 feasible. Furthermore, all application levels are broken down into five successive technological development stages. This allows a structured and clear presentation that can be helpful to identify innovative technologies and business models in the Industry 4.0 environment. For both areas (product and production) individual application levels are displayed as rows and development levels as columns. The group products are divided into levels of sensors and actuators, communication and connectivity, data storage and exchange of information, monitoring, product-related IT services and business models. The production process side includes data processing in production, machine-to-machine communication, company-wide networking with production, infrastructure of information and telecommunication technology in production, humanmachine interfaces and efficiency with small batches (VDMA, 2015).

Table 2. VDMA maturity levels merged with added values (excerpt)

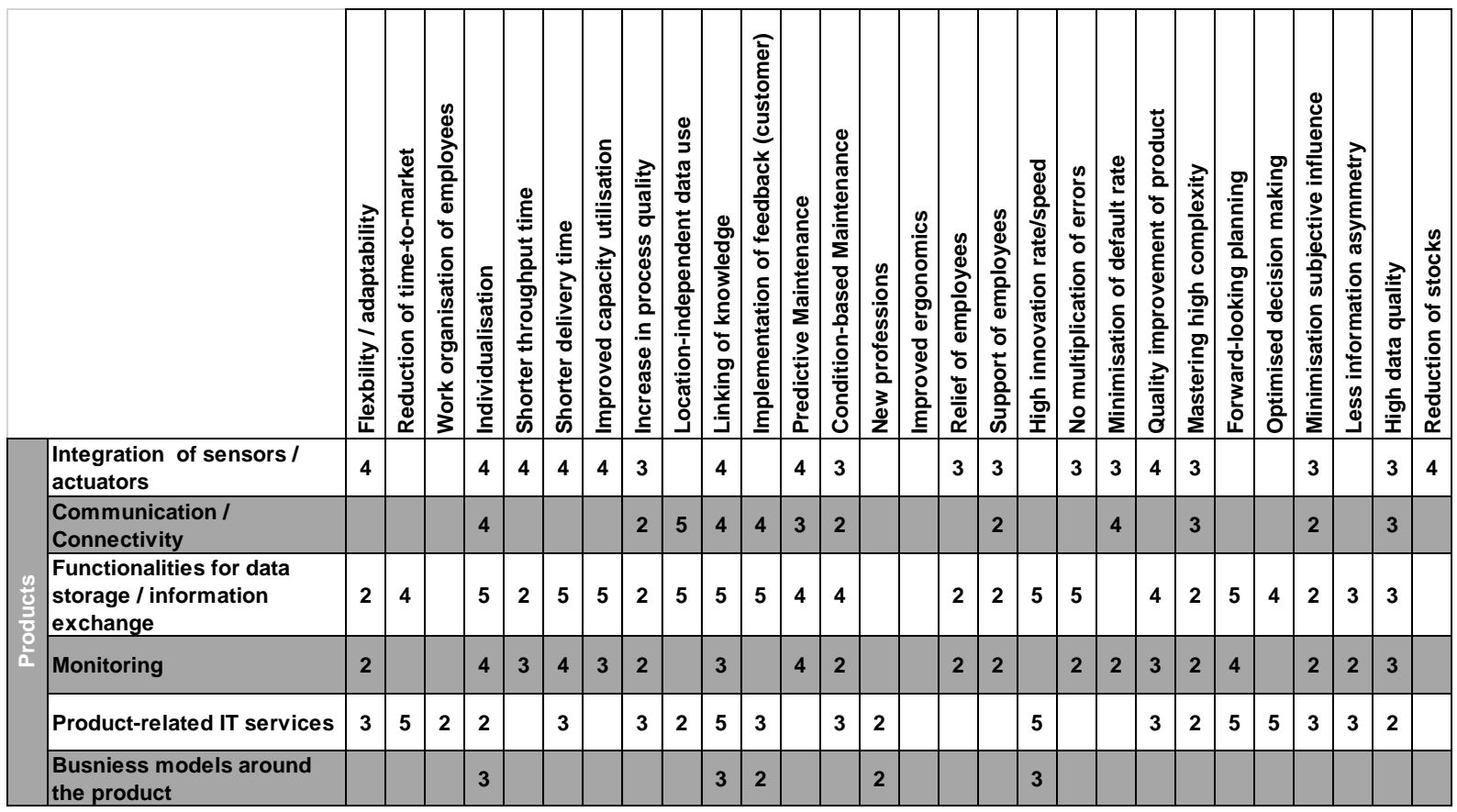

\subsection{Merging of VDMA maturity levels with added values of Industry 4.0}

In order to achieve a qualitative assessment, the added values associated with Industry 4.0 are complemented. A variety of these advantages was identified and then summarised on the basis of different sources like Botthof and Hartmann (2015), Kaufmann (2015), Eversheim (1997), Roth (2016), Horst et al. (2015) and McKinsey Digital (2015).

The implementation of Industry 4.0 is a step-by-step process. Using the VDMA model, presented in chapter 3.1, each application level is divided into five steps. At each of these application levels different added values are generated depending on the current stage, meaning depending on the degree of digitalisation. Table 2 represents an excerpt of the matrix, which has been developed to address this issue. The elaborated overall added values (columns) have been assigned to each application level (rows). It shows which application level is associated with which added value, depending on how far 
digitalisation has progressed. This means that the tool can be used by any company, regardless of its current status.

This matrix has to be read using the VDMA toolbox. The numbers within the matrix refer to the development levels. 1 means no Industry 4.0 (first level) and 5 in turn is the highest development stage on the current application level. The numbers thus show which additional added values emerge at which Industry 4.0 level.

\subsection{Industry 4.0 Relation in CPM/PDD}

On the basis of Table 2, a Relation can now be described that allows within the PDD evaluation step an assessment of the added value of the Industry 4.0 application in the assembly system. To illustrate this, the example of the connection between screw technology and clamping device from section 2 is used again (Figure 5).

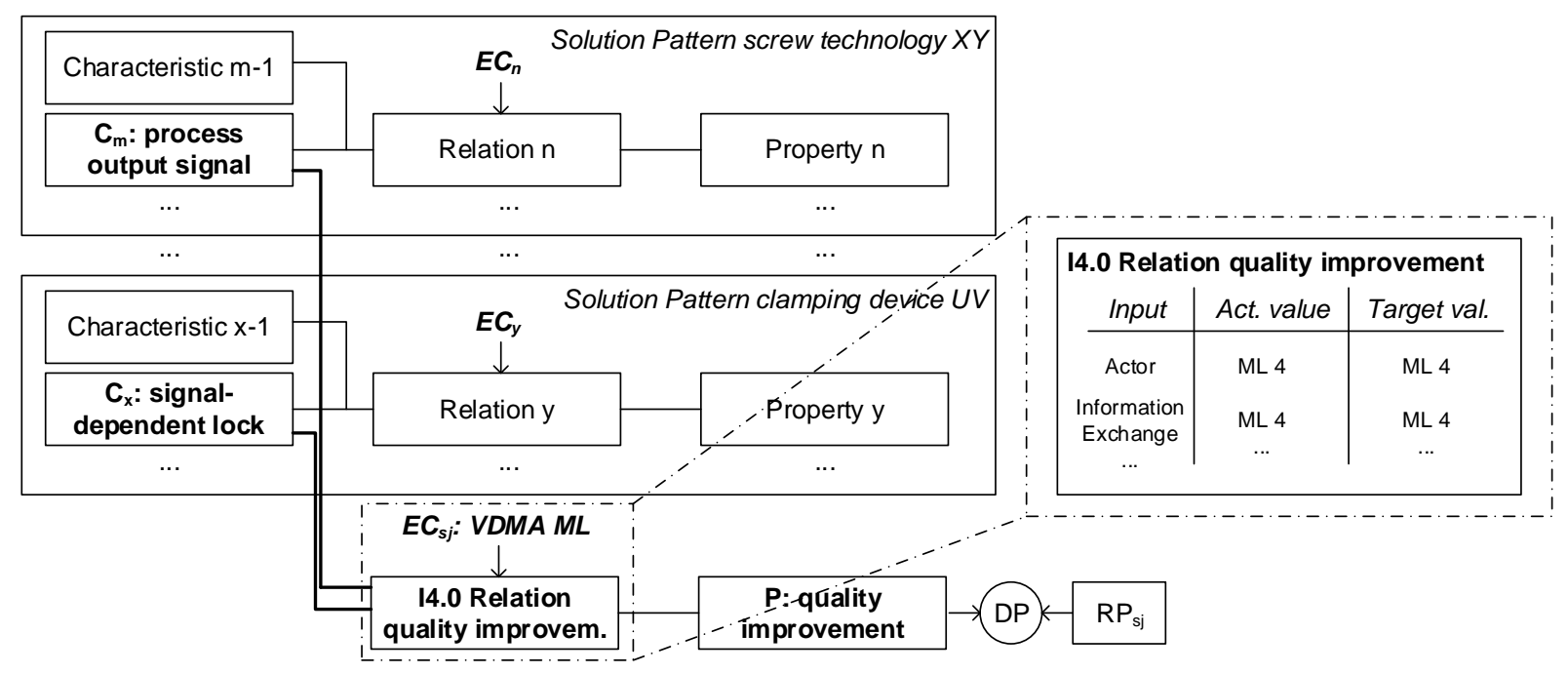

Figure 5. Example Industry 4.0 Relation for added-value assessment

Among others, the screw technology is selected as a Solution Pattern. The clamping device is selected similarly or it is designed product-specifically. However, this does not change the fact that this is also a Solution Pattern. Assuming that an added value of the assembly system should be that no faulty screw connections can be passed without being noticed, then a Required Property (System, $\mathrm{RP}_{\mathrm{sj}}$ ) has to be defined against which the intended solution can be analysed and evaluated in the PDD logic. The relation required for this is a column of Table 2: In order to ensure the Required Property, besides others, an actuator system and data exchange at least at maturity level 4 are required. The VDMA toolbox serves as an External Condition (system, $\mathrm{EC}_{\mathrm{sj}}$ ). Depending on the Characteristics selected, the assembly system is assigned a corresponding actual Property that can now be compared with the Required Property. Thus, the added value of the solution can already be evaluated and considered in the design process.

\section{SUMMARY AND OUTLOOK}

This contribution shows that the CPM/PDD approach can be applied to the design process of assembly systems in addition to classical product development and the development of manufacturing systems. Due to the special features of assembly systems an exact differentiation between product- and systemrelated Required Properties as well as External Conditions is necessary. In order to make the added value of Industry 4.0 applications in the field of assembly systems assessable by means of CPM/PDD, the established maturity model of the VDMA was merged with the added value of Industry 4.0 expected in the literature. This result is used in a concept for an Industry 4.0 Relation that connects the Characteristics in selected Solution Patterns with the desired Industry 4.0 Properties of the production equipment. On behalf of this Relation, an evaluation of the Industry 4.0 specific added value of the production equipment can be carried out within the standard PDD process.

Since the above considerations were initially made only with regard to assembly systems, the concept of the Industry 4.0 Relation has to be transferred to manufacturing systems in future work. In addition, 
considerations must be made as to how this qualitative evaluation approach can be converted into a quantitative assessment model on the basis of real production data. Detailed data concerning production equipment are often available in the context of the KPI Overall Equipment Effectiveness (OEE). In an intermediate stage, a mixed evaluation on the basis of the common types of waste according to Ohno (1988) is also conceivable for the evaluation of the added value of production equipment.

\section{REFERENCES}

Bauernhansl, T., Hompel, M. and Vogel-Heuser, B. (2014), Industrie 4.0 in Produktion, Automatisierung und Logistik: Anwendung - Technologien - Migration, Springer Fachmedien, Wiesbaden. https://doi.org/10.1007/978-3-658-04682-8

Botthof A. and Hartmann E. (2015), Zukunft der Arbeit in Industrie 4.0, Springer Vieweg, Berlin. https://doi.org/10.1007/978-3-662-45915-7

Bullinger, H. J. (1986), Systematische Montageplanung, Carl Hanser Verlag, München, Wien.

Crostack, A., Binz, H. and Roth, D. (2014), Concept of modelling the failure mode effects analysis (FMEA) on the base of characteristics-properties modelling (CPM), 58th Ilmenau Scientific Colloquium, Technische Universität Ilmenau, September 8 - 12.

Deubel, T., Zenner, C., Bley, H. and Weber, C. (2006), "Adaptation of a new Design Method for the Requirement-Driven Planning of Manufacturing Systems", Proceedings of the 16th CIRP International Design Seminar - Design \& Innovation for a Sustainable Society, Kananaskis, Alberta, Canada, July 16 19, Paper No. 10061, pp. 529-534.

Eversheim, W. (1997), Organisation in der Produktionstechnik - Arbeitsvorbereitung, Springer, Berlin.

Feldmann, K. and Slama, S. (2001), "Highly flexible assembly - scope and justification: Hochflexible Montage Anwendungsbereich und Wirtschaftlichkeitsnachweis", 51st General Assembly of CIRP: Nancy/France, Aug 19-25, Bern, Edition Colibri, Elsevier, 2001 (CIRP Annals, 50), pp. 489-498. https://doi.org/10.1016/s0007-8506(07)62987-4

Horst, A., Heribert, M., Pinkwart, A. and Reichwald, R. (2015), Management of Permanent Change, Springer Gabler, Wiesbaden. https://doi.org/10.1007/978-3-658-05014-6

Karger, D.W. and Bayha H.F. (1987), Engineered Work Measurement, Industrial Press, New York.

Kaufmann, T. (2015), Geschäftsmodelle in Industrie 4.0 und dem Internet der Dinge: Der Weg vom Anspruch in die Wirklichkeit, Springer Vieweg, Wiesbaden. https://doi.org/10.1007/978-3-658-10272-2

Kiel, D., Müller, J., Arnold, C., Voigt, K.-I. (2017), "Sustainable Industrial Value Creation: Benefits and Challenges of Industry 4.0", The XXVIII ISPIM Innovation Conference - Composing the Innovation Symphony, Vienna/Austria, June 18-21. https://doi.org/10.1142/s1363919617400151

Köhler, C., Conrad, J., Wanke, S. and Weber, C. (2008), "A matrix representation of the CPM/PDD approach as a means for change impact analysis", International Design Conference - Design 2008, Dubrovnik/Croatia, May 19 - 22, DS 48: Proceedings of the Design 2008, University of Zagreb, pp. 167-174. https://dx.doi.org/10.22028/D291-22502

Lotter, B. and Wiendahl, H.P. (2012), Montage in der industriellen Produktion: Ein Handbuch für die Praxis, Springer Vieweg, Heidelberg. https://doi.org/10.1007/978-3-642-29061-9

Moon, I., Lee, G., Park, J., Kiritsis, D., Von Cieminsk, G. (2018), Advances in Production Management Systems: Smart Manufacturing for Industry 4.0, Springer, Cham.

McKinsey Digital (2015), Industry 4.0 - How to navigate digitization of the manufacturing sector, McKinsey \& Company.

Ohno, T. (1988), Toyota Production System - Beyond large-scale production, Productivity Inc., Portland.

$\mathrm{PwC}$ and Strategy\& (2014), Industrie 4.0: Chancen und Herausforderungen der vierten industriellen Revolution. [online] PwC and Strategy\&. Available at: https://www.strategyand.pwc.com/media/file/Industrie-4-0.pdf (01.10.2018).

PwC (2018), Global Digital Operations Study 2018 Digital Champions: How industry leaders build integrated operations ecosystems to deliver end-to-end customer solutions. [online] PwC. Available at: https://www.strategyand.pwc.com/media/file/Global-Digital-Operations-Study_Digital-Champions.pdf (28.11.2018).

Roth, A. (2016), Einführung und Umsetzung von Industrie 4.0: Grundlagen, Vorgehensmodell und Use Cases aus der Praxis, Springer Gabler, Berlin. https://doi.org/10.1007/978-3-662-48505-7

Ustundag, A., Cevikcan, E. (2018), Industry 4.0: Managing The Digital Transformation, Springer International Publishing AG, Cham, Switzerland.

Wanke, S., Conrad, J. and Köhler, C. (2007), "Verhaltensbeschreibende Produktkataloge: Ein Anwendungsbeispiel der Solution Patterns des CPM/PDD Ansatzes", In: Meerkamm, H. (Ed.): Design for $X$ - Beiträge zum 18. Symposium (Neukirchen, 11. and 12. Oktober 2007), The Design Society, Lehrstuhl für Konstruktionstechnik, Erlangen, pp. 93-102. https://dx.doi.org/10.22028/D291-22485 
VDMA. (2015), Leitfaden Industrie 4.0, VDMA Verlag, Frankfurt/Main

Vullings, R. and Heleven, M. (2015), Not Invented Here: Cross-Industry Innovation, BIS Publishers, Amsterdam.

Weber, C. (2005), Cpm/Pdd: An Extended Theoretical Approach To Modelling Products And Product Development Processe, Fraunhofer-IRB-Verlag, Stuttgart. In: Bley, H., Jansen, H., Krause, F.-L. and Shpitalni, M. (Eds.), Proceedings of the 2nd German-Israeli Symposium on Advances in Methods and Systems for Development of Products and Processes, TU Berlin / Fraunhofer-Institut für Produktionsanlagen and Konstruktionstechnik (IPK), 07.-08.07.2005, pp. 159-179.

Weber, C. and Werner, H. (2000), "Klassifizierung von CAx-Werkzeugen für die Produktentwicklung auf der Basis eines neuartigen Produkt- und Prozessmodells", 11. Symposium Design for X, Schnaittach, October 12 - 13, pp. 126-143.

Weck, M. and Brecher, C. (2006), Werkzeugmaschinen 2: Konstruktion und Berechnung, Springer Vieweg, Berlin. https://doi.org/10.1007/3-540-30438-x

Westkämper, E. (2006a), "Research for Adaptive Assembly", First CIRP International Seminar on Assembly Systems, Stuttgart, November 15 - 17, 2006, Fraunhofer-IRB-Verl., Stuttgart, pp. 9-15. , ISBN 978-38167-7213-2

Westkämper, E. (2006b), Produktion: Wandlungsfähigkeit der industriellen Produktion, TCW-Report 44, TCW Transfer-Centrum, München. DOI 3-931511-88-X

Wildemann, H. (2018), Produktivität durch Industrie 4.0, TCW Transfer-Centrum, München 